\title{
TRANSFERÊNCIA DE MASSA GÁS-LíQUIDO EM COLUNA DE AERAÇÃo
}

\section{MASS TRANSFER GAS-LIQUID IN COLUMN OF AERATION}

\author{
MARCIO RICARDO SALLA \\ Engenheiro Civil. Professor. Doutor/UFU/Uberlândia \\ HARRY EDMAR SCHULZ \\ Engenheiro Civil. Professor Titular/USP/São Carlos
}

Recebido: 31/05/07 Aceito: 27/04/08

\section{RESUMO}

Neste trabalho estuda-se a transferência de massa gás-líquido a partir de bolhas de ar para a água, geradas por um difusor de ar, em uma coluna de aeração, mudando a vazão de ar de $400 \mathrm{~L} / \mathrm{h}$ a $2000 \mathrm{~L} / \mathrm{h}$, o nível de água de $0,50 \mathrm{~m}$ a $1,80 \mathrm{~m}$, cujas taxas de aplicação superficial de ar variaram de $3,1 \mathrm{~L} / \mathrm{m}^{2}$.s a $15,4 \mathrm{~L} / \mathrm{m}^{2}$.s. Várias características hidrodinâmicas foram medidas, tal como a velocidade ascensional das bolhas de ar e seus diâmetros, fundamentais para verificar o coeficiente de transferência de massa que estão na literatura, usando um equipamento laser para velocimetria não-intrusiva. Após os estudos da transferência de massa, foi concluído que a vazão de ar entre $400 \mathrm{~L} / \mathrm{h}$ e $800 \mathrm{~L} / \mathrm{h}$ e o nível de água de $1,80 \mathrm{~m}$ apresentou a maior eficiência de transferência de massa, garantindo para estas medidas, dentro da coluna em estudo, maior quantidade de oxigênio dissolvido.

PALAVRAS-CHAVE: Aeração, difusor, velocimetria nãointrusiva, equipamento laser, transferência de massa gáslíquido.

\section{INTRODUÇÃO}

$\mathrm{Na}$ natureza, caso não houvesse a interferência humana, apenas a área superficial do curso de água, que fica em contato com o ar, e os obstáculos naturais, que aumentam essa área, imporiam as limitaçóes para o desenvolvimento da vida nos diferentes ambientes.

Nos dias atuais a realidade é um pouco diferente, onde a autodepuração dos rios não é suficiente para eliminar os poluentes presentes na água, pois as quantidades de esgotos domésticos e industriais lançadas nestes rios são maiores do que a capacidade dos processos naturais de torná-las inertes. As indústrias lançam muitas vezes poluentes não biodegradáveis nos cursos de água (tais como compostos inorgânicos e metais pesados), os quais se acumulam nos ambientes naturais. Os esgotos domésticos, por outro lado, são constituídos geralmente de matéria orgânica, que é biodegradável. Porém, o consumo dessa matéria orgânica é feito por microrganismos presentes na água cuja sobrevivência depende da quantidade de oxigênio dissolvido disponível na água. Portanto, a concentração insuficiente de oxigênio dissolvido implicará em menor crescimento de microrganismos, diminuindo degradação de poluentes na água. Por esse motivo é preciso gerar mecanismos que façam com que a concentração de oxigênio dissolvido na água aumente artificialmente. Os processos de aeração artificial utilizam-se do aumento do transporte turbulento tanto pelo aumento da difusão turbulenta quanto pelo aumento da área da interface de troca entre o ar e a água.

Dentre estes métodos destacam-se a agitação mecânica com hélices ou tur- binas (Neder, 1994 apud Innocentini, 1996), bolhas ascensionais emitidas por difusores de ar que aumenta a taxa de troca global de massa na interface entre as bolhas e a água (Shiau, 1995 apud Innocentini, 1996), estruturas hidráulicas existentes em reservatórios e rios, tais como remanso hidráulico, ressalto hidráulico e queda livre de água (Gulliver \& Rindels, 1993).

A eficiente aplicabilidade de aeração artificial em cursos d'água ou em etapa de tratamento de água ou esgoto advém de resultados obtidos em estudos de colunas estáticas. Visto que o objetivo principal de todos os processos de aeração é determinar quais os reais aspectos hidrodinâmicos efetivamente presentes na transferência de massa da fase gasosa para a fase líquida, o presente estudo apresenta as influências da velocidade ascensional e diâmetro das 
bolhas. Também, justifica-se a contribuição do presente trabalho devido à possível aplicação em modelagens de colunas, principalmente de ozonização, encontradas em Singer (2000), Zhou (1994), entre outros.

\section{METODOLOGIA}

\section{Descrição das instalações utilizadas}

\section{Coluna}

A coluna utilizada foi construída com seção transversal quadrada de $0,19 \mathrm{~m}$ de lado e $2.00 \mathrm{~m}$ de altura, com 2 faces paralelas de acrílico e 2 faces paralelas de vidro, ambas com espessura de $1,50 \mathrm{~cm}$, juntamente com fundo de acrílico de mesma espessura, conforme a Figura 1. As faces de acrílico e de vidro são planas para evitar distorções e necessidade de correçôes geométricas das imagens registradas.

As faces de vidro têm a finalidade de facilitar a visualização das bolhas ascensionais e a captura de imagens por câmera de alta resolução (estudo do campo de velocidade e diâmetro equivalente das bolhas). As faces de acrílico facilitam a perfuração das tomadas de água e demais trabalhos mecânicos. $\mathrm{O}$ acrílico também permite boa penetração da folha de luz do laser. Porém, por ser mais susceptível a ações mecânicas (arranhões, opacidade da superfície), garante-se a manutenção da coluna para os próximos trabalhos através do uso das paredes de vidro. $\mathrm{O}$ travamento ao longo da coluna foi feito com barras de aço galvanizado roscáveis, espaçados em $15 \mathrm{~cm}$, colocados nos dois lados da coluna.

A coluna foi fixada apenas pelas extremidades em estrutura de aço, mantendo-a estável e fixa, com os entornos livres para a visualização das bolhas e captura das imagens. O difusor de gás utilizado foi instalado no centro da base interna da coluna. Nesta mesma base foi instalada saída de água, próxima a um dos vértices da seção transversal, utilizada para esvaziar a coluna ou para recircular água quando se procede a desaeração por meio de motor-bomba de $1 / 3 \mathrm{cv}$.

A base da coluna é removível, o que possibilita a substituição de difusores de diferentes características para estudo de transferência de massa. O difusor utilizado foi de plástico micro- poroso com as dimensões de $75 \mathrm{~mm}$ de diâmetro na base, $70 \mathrm{~mm}$ de altura e poros de $20 \mu \mathrm{m}$ para vazão máxima de ar de $3 \mathrm{~m}^{3} / \mathrm{h}$. A vazão de ar que passou pelo difusor foi medida em rotâmetro para ar graduado de $200 \mathrm{~L} / \mathrm{h}$ a $2000 \mathrm{~L} / \mathrm{h}$, com mecanismo de ajuste fino de vazão.

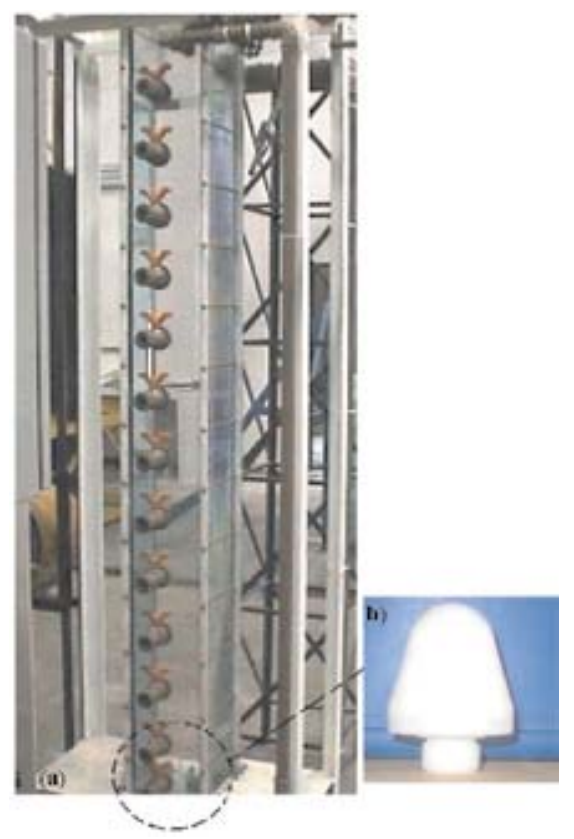

Figura I - (a)-Coluna utilizada; (b)-Difusor microporoso

Laser

A vantagem do uso da fonte de laser é a não interferência de sondas no escoamento, as quais modificam o escoamento normal do líquido.

Existem dois procedimentos que estão sendo utilizados atualmente para determinar a velocidade em escoamentos através do uso do laser, que são a Velocimetria com Laser-Doppler (VDL) e a Velocimetria a Laser por Processamento de Imagens (VLPI).

A VDL consiste na avaliação da velocidade através do estudo do efeito Doppler na envoltória de um feixe de laser que atinge uma partícula em um pequeno volume de trabalho, baseado na interferência dos feixes e criação de "franjas" de luz por onde transita a partícula. Sua utilização tem grande importância na determinação de velocidades pontuais de um escoamento.

Já a VLPI possibilita a determinação de todo o campo instantâneo de velocidades em uma região bidimensional do escoamento. No método VLPI, uma folha de laser expandida através de um conjunto de lentes ilumina o escoa- mento. Com a utilização de câmera de alta resolução, as imagens das partículas que se deslocam dentro da área de estudo são gravadas. O uso do laser é conveniente porque o mesmo fornece luz altamente concentrada para que as partículas presentes no meio reflitam esta luz com intensidade suficiente para que suas posições sejam registradas em equipamentos ópticos, como câmeras fotográficas e filmadoras.

As imagens gravadas são comumente analisadas de duas formas: a análise de correlação e a análise por rastreamento de partículas. De forma simples, o rastreamento de partículas acompanha o movimento de partículas isoladas, registrando posiçôes e intervalos de tempo. Contudo, quando o escoamento é turbulento, pode haver a "sobreposição" de partículas, acarretando dificuldades para identificar "qual partícula registrada seguiu qual caminho". Nesse caso, uma análise de todo o campo é necessária, buscando-se a situação mais provável para o escoamento. Como se trata de um processo estatístico, no qual posiçōes são correlacionadas em tempos sucessivos, este método recebeu o nome de Análise de Correlação.

Os principais componentes da VLPI são descritos a seguir.

- Fonte de laser

Para a realização deste trabalho foi utilizado laser de vapor de cobre, com alta taxa de repetição de pulsos de iluminação, da marca Oxford. Este laser oferece pulsos de iluminação de alta potência, que propicia uma folha de luz de alta densidade $\left(\mathrm{W} / \mathrm{m}^{2}\right)$. As potências médias na saída do feixe estão entre 10 e $20 \mathrm{~W}$, com uma taxa de repetição de pulsos de $10 \mathrm{kHz}$, com duração do pulso entre 20 e 60 ns.

- Bloqueador-atenuador e conversor de feixe

Como pode ser visto na Figura 2, na saída da geração do laser há um bloqueador e um atenuador do feixe do laser, que podem ser manuseados manualmente ou por mecanismo de controle. Quando o bloqueador está em funcionamento, não há transmissão da luz laser. Com o atenuador, a potência de saída do laser é diminuída em $90 \%$.

A finalidade do conversor é introduzir o feixe na fibra óptica, a qual conduz a luz ao longo de grandes distâncias. Dificuldades operacionais existem, como a necessidade de alinhamento 
do feixe de luz antes da introdução na fibra ótica, para que haja a máxima potência disponível. Contudo, um desvio do ponto focal pode implicar em "queima” da ponta da fibra, ou seja, escurecimento e impedimento da passagem normal da luz.

\section{- Fibra óptica}

Como já foi mencionada, a finalidade da fibra óptica é transportar o feixe de luz laser a grandes distâncias. Devido ao problema de atenuação da luz, o uso da fibra óptica implica em perda inevitável de potência de iluminação. Em média a perda desta potência é de $30 \%$ em 15 m de fibra óptica.

- Gerador do plano de luz

Trata-se de um conjunto de lentes convergentes e divergentes, que tem a finalidade de gerar um plano de luz. $\mathrm{O}$ plano de luz é a porção iluminada do escoamento, onde são determinados os campos de velocidade. A espessura da folha de luz laser é de aproximadamente $4 \mathrm{~mm}$, com um ângulo de abertura de $28^{\circ}$.

\section{- Câmera}

A câmera tem a finalidade de captar as imagens na área selecionada do escoamento iluminada pelo plano de luz laser. $O$ ângulo formado entre o plano de luz laser e o eixo longitudinal da objetiva da câmera deve ser o mais próximo possível de $90^{\circ}$, a fim de que os campos de velocidades obtidos através de imagens sucessivas tenham uma representação real.

As câmeras utilizadas para obtenção de imagens sucessivas devem permitir a visualização de deslocamentos sucessivos de partículas, através de um grande número de exposições por segundo, a fim de que possam ser determinados adequadamente os campos de velocidade bidimensionais. A câmera utilizada neste trabalho tem uma resolução que varia de 512 por 512 pixels a $1 \mathrm{~K}$ por $1 \mathrm{~K}$ pixels, da marca Kodak. A resolução da câmera em número de pixels é importante para a nitidez da imagem e para a geração dos valores numéricos no processo de tratamento da imagem. Na calibração da câmera, uma régua graduada em centímetros colocada no plano da folha de luz, permite ao programa utilizado transformar a informação de centímetros para número de pixels.

- Processamento das imagens

A calibração e as imagens obtidas através da câmera foram trabalhadas em programa computacional
Visiflow ${ }^{\circledR}$, objetivando a determinação das bolhas.

\section{Metodologia dos ensaios}

\section{Diâmetro equivalente das bolhas}

A determinação do tamanho das bolhas é fundamental para quantificar a área interfacial de troca de massa. Quanto menor for o diâmetro das bolhas ascensionais, maior será a área interfacial específica das bolhas. Conseqüentemente, maior será também o coeficiente de transferência de massa global.

As imagens foram capturadas na região central da coluna, onde existe maior densidade de bolhas em função das inevitáveis coalescências de bolhas (a coalescência diminui a área interfacial de contato entre bolhas e meio líquido causando a queda de eficiência de transferência de massa gás-líquido).

No processo de obtenção das imagens, o plano de luz laser iluminou o escoamento ascensional das bolhas e uma máquina fotográfica digital profissional, da marca Kodak, possibilitou captar grande quantidade de bolhas nítidas nessa região.

No processo de calibração, a área delimitada para captura da imagem e fixação do número de pixels foi de $0,19 \mathrm{~m}$ (abscissa) por $0,14 \mathrm{~m}$ (ordenada). A base da área de captura de imagem estava posicionada a $0,80 \mathrm{~m}$ acima da base interna da coluna.

$\mathrm{Na}$ Figura 3 está apresentada uma imagem das bolhas ascensionais na região central da coluna, iluminada pelo plano de luz laser e captada por máquina fotográfica digital profissional com resolução de 6 megapixels e tempo de exposição de $1 / 250$ segundos. dos campos de velocidades ascensionais

Foram determinados os diâmetros equivalentes das bolhas para as mesmas vazôes do processo de transferência de massa, mantendo-se o nível de água em $1,80 \mathrm{~m}$. Para cada vazão foram obtidas 10 imagens.

Na determinação do diâmetro médio das bolhas, as imagens (fotografias) foram trabalhadas em programa computacional gráfico AutoCAD através da seguinte rotina: transferindo cada imagem para o programa computacional gráfico AutoCAD, era necessário definir um fator de escala. Este fator de escala possibilita ao programa computacional reconhecer a imagem em escala; com a imagem em escala, traçaram-se elipses (raramente círculos) ao redor das bolhas visualizadas. Em cada imagem (fotografia) traçou-se aproximadamente 120 elipses e círculos; depois de traçadas as elipses e círculos ao redor das bolhas, calculou-se a área total das bolhas traçadas; a área média das bolhas, para uma mesma imagem (fotografia), resultou da divisão entre a área total das bolhas traçadas e o número total de bolhas traçadas; finalizando, para esta mesma imagem, o diâmetro médio das bolhas resultou em $\mathrm{d}=\sqrt{4 \mathrm{~A} / \mathrm{r}}$, onde $\mathrm{A}\left(\mathrm{m}^{2}\right)$ é a área média das bolhas.

Velocidade ascensional das bolhas

As velocidades ascensionais das bolhas foram determinadas com a utilização do equipamento laser da marca Oxford e do programa computacional Visiflow $^{\circledR}$. Optou-se por determinar os campos de velocidades para as mesmas vazóes usadas no estudo do coeficiente de transferência de massa, mantendo-se o nível de água dentro da coluna fixo em 1,80 m. As imagens obtidas possibilitam visualizar toda a seção

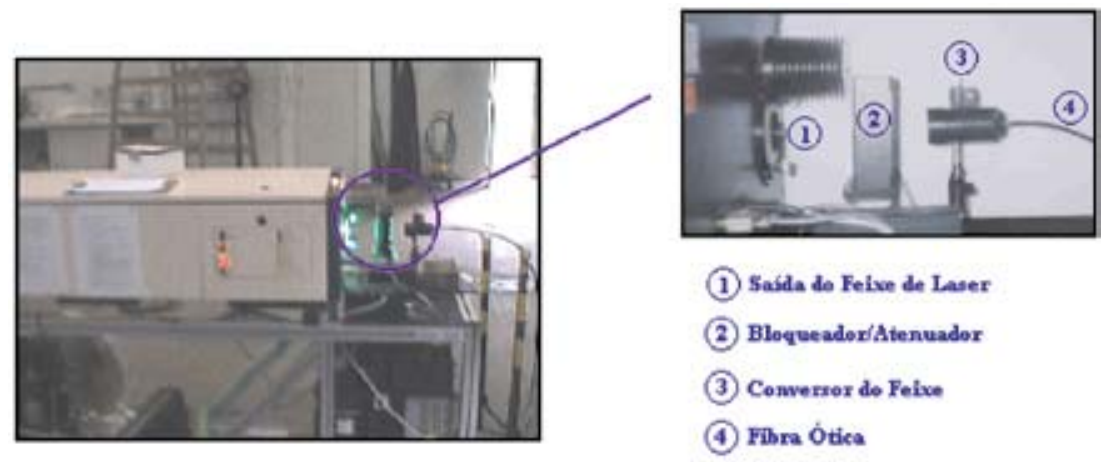

Figura 2 - Aparelho laser em funcionamento, transmitindo folha de luz até a coluna através de uma fibra ótica de $15 \mathrm{~m}$ de extensão 
transversal do escoamento ascensional das bolhas. O plano de luz de laser ficou posicionado aproximadamente no centro da coluna, pois nesta região as velocidades ascensionais das bolhas têm o valor máximo em função das coalescências, conforme mostrado na Figura 4.

Foram obtidas, para cada vazão, 4 seqüências de 10 imagens por segundo, totalizando 40 imagens para cada vazão estudada. Com as imagens obtidas pela câmera, determinaram-se os campos instantâneos de velocidade ascensional das bolhas através do programa computacional Visiflow ${ }^{\circledR}$. Convém salientar que o bom funcionamento do programa computacional Visiflow ${ }^{\circledR}$ para a obtenção dos vetores de velocidade depende da visualização de uma mesma bolha em imagens sucessivas.

Concentração de Oxigênio Dissolvido (OD)

Neste trabalho foi usado aparelho medidor de oxigênio dissolvido, modelo WTW-323, que consiste de um eletrodo ligado a um sistema e amplificação de sinal. A sonda (eletrodo) é separada do meio líquido por uma membrana permeável ao oxigênio. Quando a sonda está em contato com o líquido, o oxigênio dissolvido presente no lado líquido difunde-se através da membrana, sendo reduzido eletroquimicamente após passar por um cátodo de potencial elétrico constante, gerando uma corrente elétrica. (Momesso, A.M. - 1996)

\section{Ajuste dos parâmetros}

Estimativa da área superficial total das bolhas

Para estimar a área superficial total das bolhas é preciso que se tenha em mãos os diâmetros equivalentes das bolhas ascensionais. Jun \& Jain (1993) assumiram a área superficial total das bolhas como sendo:

$$
\mathrm{A}_{\mathrm{b}}=\frac{\mathrm{Q}_{\mathrm{a}}}{\mathrm{V}_{\mathrm{a}}} \frac{\mathrm{S}_{\mathrm{m}}}{\mathrm{V}_{\mathrm{m}}} \mathrm{L}
$$

Onde: $A_{b}$ é a área superficial total das bolhas, $\mathrm{m}^{2}$; $\mathrm{Q}_{\mathrm{a}}$ é a vazão de ar, $\mathrm{m}^{3} / \mathrm{s}$; $\mathrm{V}$ é a velocidade média das bolhas de ar, $\mathrm{m} / \mathrm{s} ; \mathrm{S}$ é a área superficial média de bolhas de ar individuais, $\mathrm{m}^{2} ; \mathrm{V}_{\mathrm{m}}$ é o volume médio de bolhas de ar individuais, $\mathrm{m}^{3}$; $\mathrm{L}$ é a distância entre

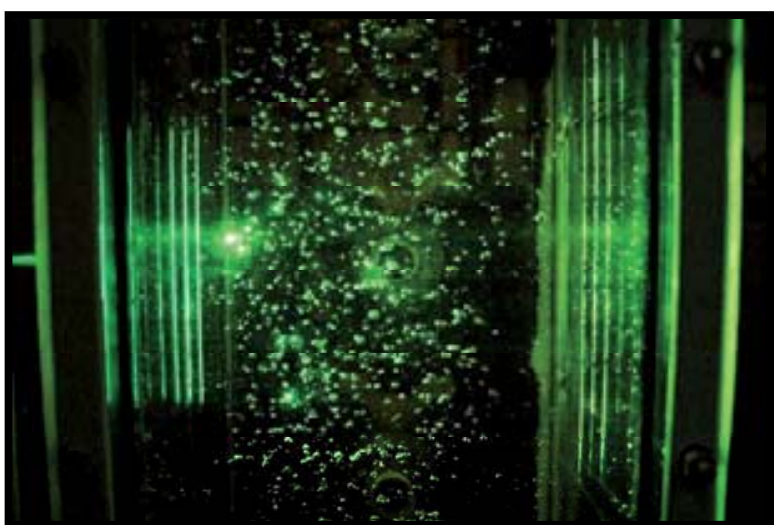

Figura 3 - Imagem das bolhas ascensionais na região central da coluna com água de abastecimento, iluminadas pelo plano de luz laser e captadas por câmera digital profissional com resolução de 6 megapixels e tempo de exposição de I/250 segundos

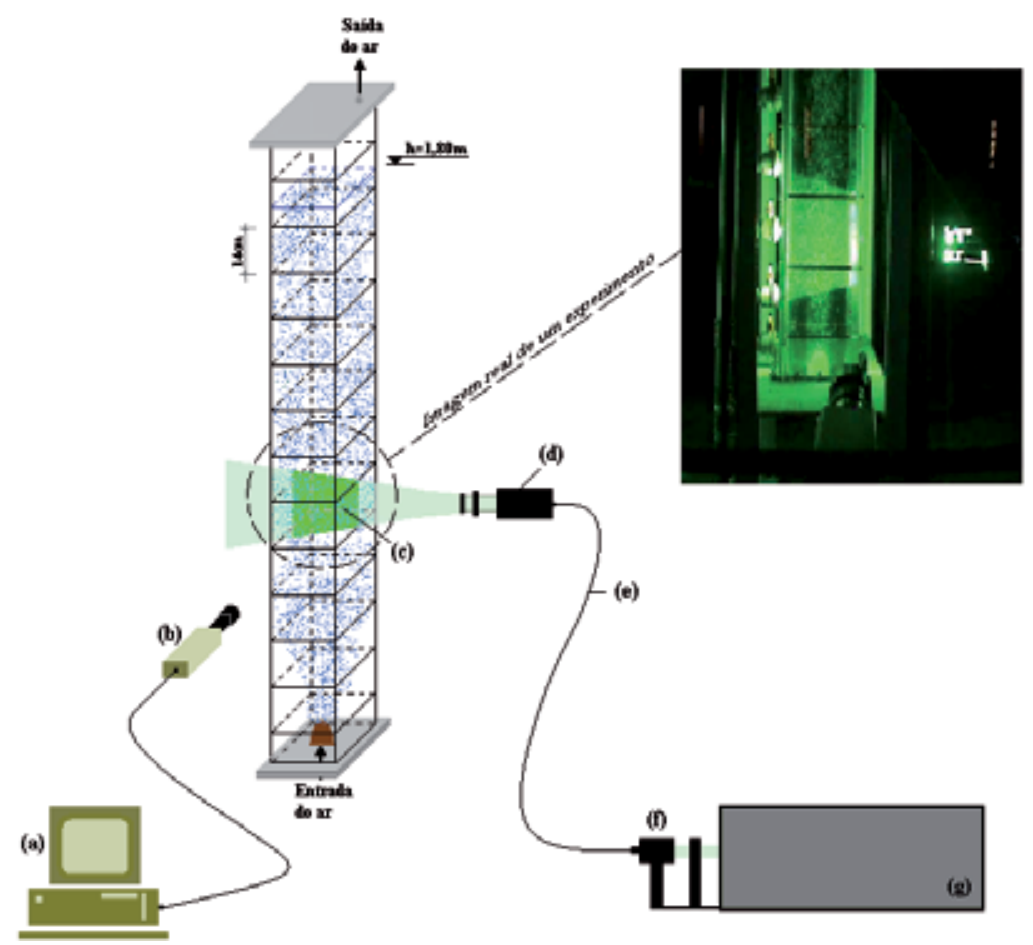

Figura 4 - Disposição dos equipamentos na determinação dos campos de velocidade ascensionais das bolhas para o nível de água em I,80 m. (a) micro-computador; (b) câmera CCD; (c) local de iluminação das bolhas pelo plano de luz laser; (d) conjunto de lentes convergentes e divergentes; (e) fibra-óptica; (f) conversor-atenuador de feixe; (g) equipamento laser utilizado com potência média de $20 \mathrm{~W}$

a saída do ar no difusor e o nível de água na coluna, $\mathrm{m}$.

A variável L é determinada através da geometria do sistema, $\mathrm{Q}_{\mathrm{a}}$ é sabido através das condiçóes experimentais. Os valores de $\mathrm{S}_{\mathrm{m}}$ e $\mathrm{V}_{\mathrm{m}}$ foram obtidos mediante a medição do tamanho das bolhas e, $\mathrm{V}_{\mathrm{a}}$ foi determinada com o uso do aparelho Laser, através de programa computacional Visiflow $^{\circledR}$.

Área transversal das bolhas

A determinação da área transversal das bolhas é fundamental para deter- 
minar a velocidade teórica de subida das bolhas. A velocidade ascensional teórica das bolhas é igual à vazão de aeração dividida pela área transversal das bolhas.

Segundo Schulz (1989), a área transversal das bolhas pode ser estimada de acordo com a seguinte equação:

$\mathrm{A}_{\text {Transv.Bolhas }}=\mathrm{A}_{\text {Transv.Total }} \frac{\mathrm{V}_{\text {Expandido }}}{\mathrm{V}_{\text {Liquido }}}$

Onde: $\mathrm{A}_{\text {Transv Bolhas }}$ é a área transversal das bolhas, $\mathrm{m}^{2} ; \mathrm{A}_{\text {Transv.Total }}$ é a área transversal da coluna, constante em toda sua altura e igual a $0,19 \mathrm{~m} \times 0,19 \mathrm{~m}, \mathrm{~m}^{2} ; \mathrm{V}_{\mathrm{E}}$ é o volume total das bolhas, igual a $0,19 \mathrm{~m} \times 0,19 \mathrm{~m} \times \mathrm{h}(\mathrm{m})$, onde $\mathrm{h}(\mathrm{m})$ é a diferença do nível de água na coluna entre o difusor ligado e desligado, $\mathrm{m}^{3}$; $\mathrm{V}_{\text {Líquido }}$ é o volume líquido total na coluna com o difusor desligado, $\mathrm{m}^{3}$.

\section{RESULTADOS E DISCUSSÕES}

\section{Curvas de aeração}

Foram realizados 40 ensaios para determinar a transferência de oxigênio na coluna d’água, variando a vazão de ar no difusor e a altura d’água na coluna. Optou-se por analisar 8 alturas d’água, em 5 vazões para cada altura, como está mostrado na Figura 5, a fim de determinar o conjunto altura d’água/vazão que propicia a maior eficiência de transferência de massa, para o formato de coluna estudado. As taxas de aplicação superficial de ar variaram de $3,1 \mathrm{~L} / \mathrm{m}^{2}$.s a $15,4 \mathrm{~L} / \mathrm{m}^{2}$.s.

A maioria dos ensaios foi realizada apenas uma vez, apesar da conveniência de realizar réplica neste tipo de experimento. Tais réplicas não foram feitas pois, mediante testes preliminares com alturas d’água e vazões próximas mas diferentes das estudadas, alcançou-se valores de concentração de oxigênio dissolvidos dentro da mesma ordem de grandeza.

Somente os primeiros ensaios com vazão de $800 \mathrm{~L} / \mathrm{h}$ tiveram que ser repetidos, porque se observou aderência de bolhas na superfície da membrana do eletrodo, o que produziu curvas de aeração (oxigênio dissolvido) não coerentes com o conjunto de dados já obtido. A inclusão do anel de PVC em torno do difusor resolveu o problema e os resultados passaram a integrar-se bem ao conjunto de dados já coletado. Os parâmetros $\mathrm{K}_{\mathrm{L}}$ a e $\mathrm{C}_{\text {s }}$ foram determinados através do ajuste das curvas de aeração, no programa computacional de regressão não linear Mathematica 4.0. Em todos os testes houve boa correlação na regressão não-linear, pois o $r^{2}$ se manteve sempre superior a 0,98 . A Figura 5 apresenta as curvas de $\mathrm{K}_{\mathrm{L}} \mathrm{a}$ (coeficiente volumétrico de transferência de massa global) em função da vazão de aeração, após efetuada correção na temperatura, visando a normalização para $20^{\circ} \mathrm{C}$, seguindo a recomendação da ASCE (1984).

Observa-se que todas as curvas são crescentes com a vazão de ar, para um mesmo nível de água. Para o nível de água de 1,40 m, o valor do coeficiente de transferência de massa para vazão de $1.600 \mathrm{~L} / \mathrm{h}$ não manteve o comportamento de aumento crescente. Uma das possíveis causas pode ser alguma contaminação da água neste experimento. A Figura 5 mostra um comportamento bem definido para todas as situaçôes de profundidade da água na coluna. Os valores dos coeficientes de transferência de massa global $\mathrm{K}_{\mathrm{L}} \mathrm{a}\left(20^{\circ}\right)$ evoluem em uma mesma nuvem de pontos, independente da profundidade da água (para a faixa de profundidades estudada). Esta independência pode implicar em simplificações para formulaçôes empíricas que buscam calcular o coeficiente de transferência de massa.

A Figura 6 mostra os mesmos dados da Figura 5 lançados em gráfico em escala logarítmica. Esta apresentação evidencia que pode ser apresentada uma aproximação tipo "lei de potência" entre os coeficientes de transferência de massa e as vazões, com expoente próximo ao valor $1 / 2$. Para colunas com as características ensaiadas, a aproximação empírica apresentada pode auxiliar nas quantificações de troca de oxigênio.

Uma aproximação na forma de evolução exponencial também foi apresentada no gráfico da Figura 7, mostrando a equação de melhor ajuste.

$\mathrm{Na}$ Figura 8 aparece o gráfico de valores previstos contra valores medidos. Observa-se um bom ajuste dos dados.

Os valores de $\mathrm{K}_{\mathrm{L}}$ a previstos $\mathrm{da}$ Figura 8 foram extraídos da equação resultante da Figura 7. De acordo com a Figura 8, todos os pontos estão dentro de uma faixa de erro de $\pm 10 \%$. Já a metade dessem pontos estão dentro de uma faixa de erro de $\pm 5 \%$.

\section{Diâmetro equivalente}

Fotografias digitais foram analisadas no programa computacional gráfico
AutoCAD para obter o diâmetro equivalente das bolhas de ar para cada vazão. Após analisadas todas as fotografias e computados os valores das áreas totais das bolhas em cada imagem, obtiveramse valores médios para os diâmetros equivalentes das bolhas em função da vazão de aeração, mantendo-se o nível de água dentro da coluna em 1,80 m. A posição onde foram feitas as imagens manteve-se igualmente constante, a $0,80 \mathrm{~m}$ acima da base interna da coluna. A Figura 9 apresenta os resultados obtidos. A Tabela 1 mostra os desvios da linha de tendência exponencial em cada ponto estudado.

De acordo com os baixos valores dos desvios entre diâmetros empíricos e teóricos (Tabela 1) constata-se a ótima qualidade da linha de tendência obtida. (Entenda-se por teórico justamente o valor calculado a partir da linha de melhor ajuste).

Como era esperado, quanto maior a vazão de aeração, maior o diâmetro equivalente médio das bolhas. Os valores médios apresentam pouco espalhamento em torno de uma tendência de crescimento exponencial.

Conforme está mostrado na Figura 7 , os valores dos coeficientes de transferência de massa global medidos para alturas líquidas variáveis, em cada vazão, situam-se dentro de um intervalo de $\pm 10 \%$. Perante este baixo intervalo, considerou-se, para este formato de coluna, a independência do valor de $\mathrm{K}_{\mathrm{L}} \mathrm{a}$ para com a profundidade da coluna de água. Com isso, adotou-se aqui a simplificação de não considerar a influência da altura da coluna no diâmetro equivalente das bolhas, especialmente para o intervalo de altura líquida estudado $(0,50 \mathrm{~m}$ até $1,80 \mathrm{~m})$. A literatura não permite chegar à mesma conclusão e recomenda-se estudar esta questão em trabalhos futuros. Certamente a altura da coluna afeta o diâmetro das bolhas, pois afeta a pressão. Se a altura for dobrada, por exemplo, a pressão aproximadamente dobra, e o volume de uma bolha cai aproximadamente pela metade.

\section{Eficiência da transferência de massa de oxigênio para a água}

A eficiência de transferência de massa permite indicar a melhor situação "geométrica" no processo de transferência para as diferentes configurações ensaiadas. As grandes variações de vazão 


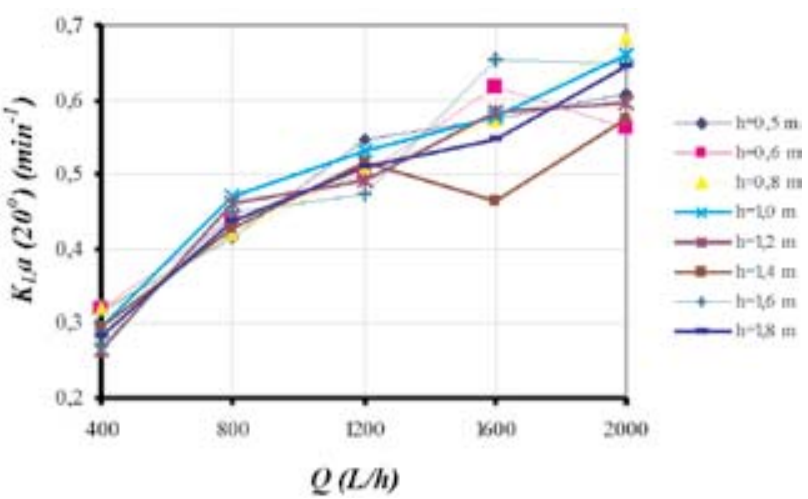

Figura $5-K_{\llcorner} a\left(20^{\circ}\right)$ em função das 5 vazões de ar estudadas na aeração utilizando diversos níveis de água na coluna

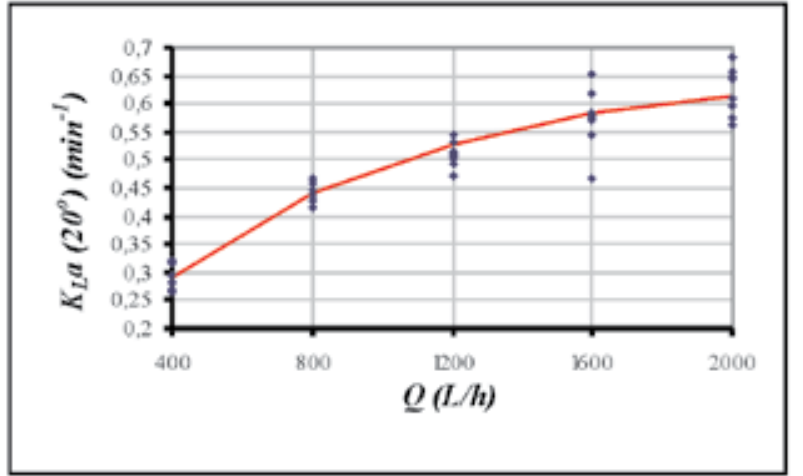

Figura 7 - Dados da Figura 5, incluindo uma curva de ajuste exponencial, $K_{L} a=0,66-0,62 e^{-0,00130}$

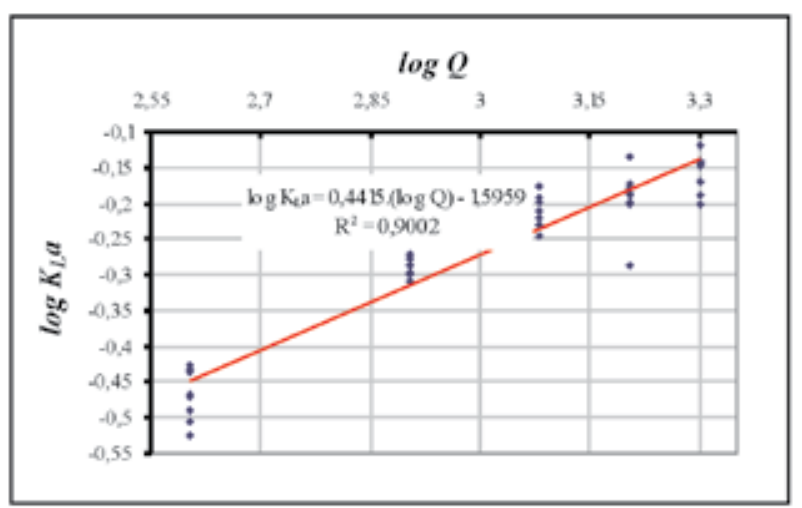

Figura 6 - Logaritmo de $K_{L} a\left(20^{\circ}\right)$ em função das 5 vazões de ar estudadas na aeração utilizando diversos níveis de água na coluna

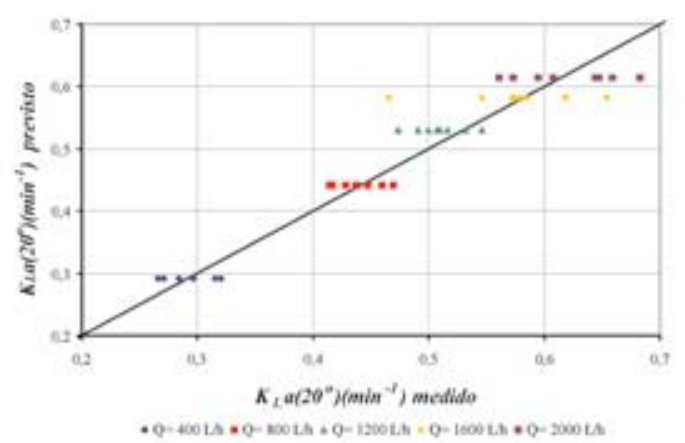

Figura 8 - Valores previstos contra valores medidos do coeficiente volumétrico de transferência de massa arlíquido global, com correção da temperatura

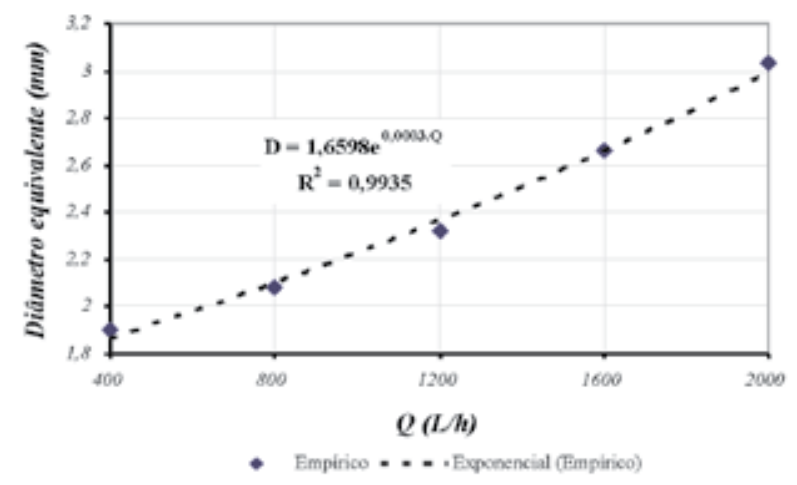

Figura 9 - Diâmetro equivalente médio das bolhas em função da vazão de aeração para nível d água em $1,80 \mathrm{~m}$ 
Tabela I - Desvios da linha de tendência exponencial para os diâmetros médios das bolhas em função da vazão de gás aplicada $(\mathrm{h}=1,80 \mathrm{~m})$ obtidos na Figura 9

\begin{tabular}{ccccc}
\hline $\begin{array}{c}\mathrm{Q} \\
(\mathrm{L} / \mathrm{h})\end{array}$ & $\begin{array}{c}\mathrm{Q} \\
(\mathrm{L} / \mathrm{min})\end{array}$ & $\begin{array}{l}\text { 4médio } \\
\text { empírico } \\
(\mathrm{mm})\end{array}$ & $\begin{array}{l}\text { 4médio } \\
\text { teórico } \\
(\mathrm{mm})(2)\end{array}$ & $\begin{array}{l}\text { Desvio } \\
(\%)(*)\end{array}$ \\
\hline 400 & 6,67 & 1,9 & 1,87 & 1,43 \\
800 & 13,33 & 2,08 & 2,11 & $-1,50$ \\
1200 & 20,00 & 2,32 & 2,38 & $-2,95$ \\
1600 & 26,67 & 2,66 & 2,68 & $-1,12$ \\
2000 & 33,33 & 3,03 & 3,02 & 0,28 \\
\hline
\end{tabular}

e do nível de água na coluna permitiram obter uma boa imagem final da evolução dessa eficiência. Segundo Innocentini (1996), quando se trata de aeração realizada por bolhas através de difusor poroso, a equação da eficiência de transferência de massa de oxigênio é:

$h=\frac{\left(\mathrm{C}_{\mathrm{s}}-\mathrm{C}_{0}\right) \mathrm{V}_{\mathrm{L}}}{\mathrm{Q} . \mathrm{X}_{02} . \mathrm{t}_{\text {ar }} . \text { taracao }_{\text {ara }}}$

Onde: $\mathrm{C}_{\mathrm{S}}$ é a concentração de saturação do oxigênio na água, em $\mathrm{mg} / \mathrm{L} ; \mathrm{C}_{0}$ é a concentração de oxigênio dissolvido no início da aeração, ou seja, concentração igual a zero em todos os ensaios realizados; $\mathrm{V}_{\mathrm{L}}$ é o volume de água contida na coluna, em litros; $Q$ é a vazão de aeração, em L/min; $X_{0_{2}}$ é a fração mássica de oxigênio no ar atmosférico, igual a 0.209; t ar a massa específica do ar atmosférico, em $\mathrm{Kg} / \mathrm{m}^{3}$; $\mathrm{t}_{\text {aeraçăo }}$ é tempo de aeração em cada ensaio, em minutos.

A Figura 10 resume os dados deste trabalho. Visualiza-se a mesma tendência geral em todas as curvas, nas quais a eficiência decresce com o aumento da vazão. Para uma mesma vazão, observase que o valor da eficiência aumenta com o aumento do nível de água dentro da coluna.

Abandonando a visão geral e atentando aos detalhes das curvas, observa-se a existência de duas regiōes: a primeira região corresponde às profundidades de $0,50 \mathrm{~m}$ a $1,00 \mathrm{~m}$, cujos dados se localizam na parte inferior $\mathrm{da}$ figura. Essas curvas apresentam tendência decrescente sem haver algum ponto de inflexão próximo à vazão de 800 $\mathrm{L} / \mathrm{h}$; a segunda região corresponde às profundidades de $1,20 \mathrm{~m}$ a $1,80 \mathrm{~m}$, cujos dados se localizam na parte superior da figura. As duas regiôes ficam bem demarcadas pela existência de sobreposição das curvas correspondentes às profundidades de $1,00 \mathrm{~m}$ e $1,20 \mathrm{~m}$, cada qual com sua tendência, porém ocupando o mesmo espaço da figura.

Observa-se que a maior eficiência de transferência foi obtida para vazão de aeração de $800 \mathrm{~L} / \mathrm{h}$, com o nível de água na coluna de $1.80 \mathrm{~m}$. É possível inferir que haja um ponto de máximo para alguma vazão entre $400 \mathrm{~L} / \mathrm{h}$ e $800 \mathrm{~L} / \mathrm{h}$, para esta mesma profundidade, visto que, de acordo com a Figura 10 , existe apenas uma interligação entre os pontos para cada nível líquido, não ocorrendo variação linear da eficiência em função da vazão. Ou seja, não foi aplicada nenhuma linha de tendência sobre esta figura. $\mathrm{O}$ mesmo comportamento é observado para a profundidade de 1,60 m. Para as demais profundidades não se observa a existência de um ponto de máximo entre os extremos de vazão estudados neste trabalho. A existência de um ponto de máximo sugere que mais experimentos sejam realizados, buscando aumentar ainda mais a eficiência.

\section{Campo de velocidade ascensional das bolhas}

Os campos de velocidades ascensionais das bolhas foram determinados com o uso do Laser e de programa computacional Visiflow ${ }^{\circledR}$. vam-se componentes laterais de velocidade (transversais), conforme pode ser observado na Figura 11. Efetuou-se a média dos campos de velocidade sobre as 40 imagens. Isto não representa a média real do escoamento, devido ao pouco tempo de aquisição das imagens. Contudo, permite observar que as flutuaçôes transversais são bem amenizadas e que o campo principal (médio) tende a ser vertical.

Concluída a obtenção dos campos de vetores de velocidade, foi determina-
Nos campos instantâneos obser- do o campo médio para as 40 imagens de cada vazão, totalizando 5 campos médios de velocidade.

Como mencionado, os vetores resultantes dos campos médios de velocidade devem ser verticais. Observou-se que nem todos os vetores são verticais e, portanto, mais campos deveriam ser computados. A literatura da área apresenta o valor de 400 campos para se obter a convergência da média. Contudo, para obter o valor médio da velocidade de ascensão das bolhas, a ser usado para calcular a área interfacial total de troca e o coeficiente de transferência de massa teórica, basta utilizar a componente y (vertical) dos vetores. Em cada campo médio de velocidade foi extraído o valor da componente y de cada vetor e exportado para o Excel. Com isso, achou-se o valor da velocidade média ascensional.

Para comprovar os valores obtidos com a metodologia VLPI, estes foram comparados com os valores teóricos de velocidade ascensional das bolhas. A velocidade média teórica é a divisão da vazão de ar aplicada pela área transversal das bolhas. Através da equação (2) foi possível determinar a área transversal das bolhas variando o nível de água na coluna e a vazão de ar. Uma vez que a aquisição dos campos de velocidades empregando velocimetria a Laser foi realizada apenas com o nível de água na coluna em $1,80 \mathrm{~m}$, a Figura 12 traz a comparação entre as velocidades teóricas e experimentais (velocimetria a Laser) apenas para este nível de água dentro da coluna. O resultado da Figura 12 indica que os valores das velocidades experimentais foram superiores aos valores teóricos para quatro (04) das vazôes estudadas, sendo que os valores coincidiram para a vazão de $800 \mathrm{~L} / \mathrm{h}$. A maior diferença obser-vada entre os valores teóricos e experimentais foi da ordem de apenas $20 \%$, o que represen-ta um aspecto positivo desta comparação. Finalmente, procurou-se comparar os valores dos coeficientes de transferência de massa medidos neste trabalho com uma equação de amplo uso propostana literatura. Várias comparaçõespodem ser efetuadas. No presente trabalho apresenta-se apenas a melhor situação, obtida com o modelo de Frössling apud Motarjemi \& Jameson (1978), que pode ser visto através da Figura 13.

Como pode ser observado na Figura 13, os valores do coeficiente 


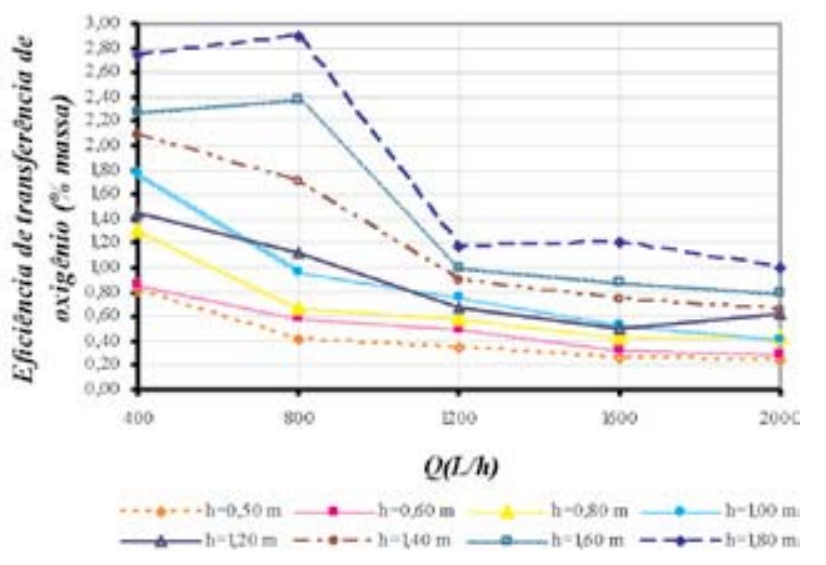

Figura 10 - Eficiência de transferência de oxigênio (\% massa) em função da vazão de aeração (L/h), utilizando vários níveis de água na coluna

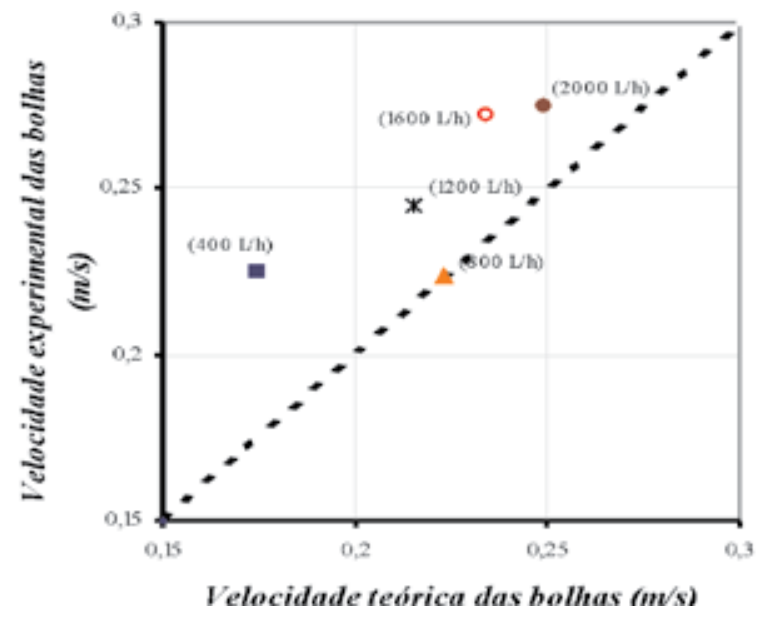

Figura I 2 - Comparação entre os valores de velocidade experimental (medida) das bolhas e a velocidade teórica das bolhas, para o nível de água dentro da coluna de $1,80 \mathrm{~m}$



Figura I I - Campo instantâneo de velocidade das bolhas $(\mathrm{Q}=2000 \mathrm{~L} / \mathrm{h}$ e hágua $=I, 80 \mathrm{~m})$, em

uma região de 0, $19 \mathrm{~m} \times 0,14 \mathrm{~m}$ localizada a $0,80 \mathrm{~m}$ acima da face interna da base, onde $Y$ é $a$ direção longitudinal da coluna e $X$ é $a$ direção transversal da coluna

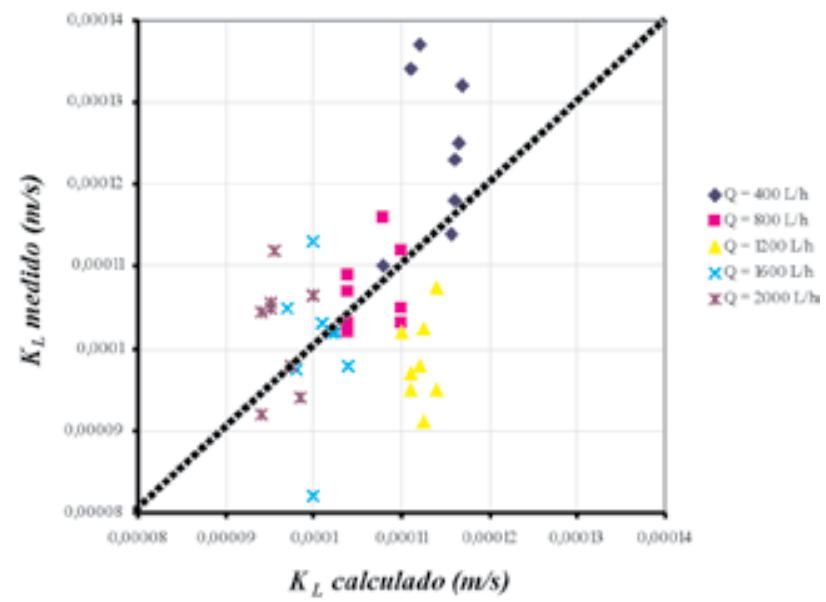

Figura 13 - Comparação dos valores de $K_{L}(\mathrm{~m} / \mathrm{s})$ obtidos neste trabalho e do Modelo de Frössling de transferência de massa medidos não seguem a tendência do modelo. Várias causas podem estar vinculadas a essa diferença. Por exemplo, um erro pode residir na consideração de que o diâmetro equivalente das bolhas e a velocidade ascensional são iguais para todos os níveis de água na coluna, para uma mesma vazão. Contudo também o modelo pode apresentar limitação para a geometria estudada, não sendo válido, eventualmente, para este tipo de aplicação. Vale lembrar que as Figuras 5 e 6 mostraram um comportamento muito parecido, com mesmas tendências de crescimento do coeficiente de transferência de massa global, que, quer-se crer, atestam pela qualidade dos dados aqui obtidos. Também a Figura 8 mostrou boa concordância entre dados previstos com a regressão obtida e os dados medidos.

\section{CONCLUSÕES}

Conseguiu-se estudar a transferência de massa de ar na água para as bolhas geradas por um difusor de ar, juntamente com as características hidrodinâmicas envolvidas neste processo, tais como campo de velocidade ascensional das bolhas e tamanho das bolhas, cujas taxas de aplicação superficial de ar variaram de $3,1 \mathrm{~L} / \mathrm{m}^{2}$.s a $15,4 \mathrm{~L} / \mathrm{m}^{2}$.s.
A avaliação do coeficiente de transferência de oxigênio para a água em diferentes condiçôes de operação compóe um conjunto de dados coerente e geram gráficos elucidativos, com comportamentos e tendências claramente visíveis, onde as correlaçōes entre o coeficiente de transferência de oxigênio e a vazão de ar mostraramse as mais promissoras para previsóes de transferência de massa. Os outros parâmetros, como a profundidade de água na coluna e o diâmetro das bolhas, embora correlacionados com a vazão, não mostraram correlação clara com o coeficiente de transferência de massa. Contudo, a vazão de ar entre 
$400 \mathrm{~L} / \mathrm{h}$ e $800 \mathrm{~L} / \mathrm{h}$ e o nível de água de $1,80 \mathrm{~m}$ apresentou a maior eficiência de transferência de massa, garantindo para estas medidas, dentro da coluna em estudo, maior quantidade de oxigênio dissolvido.

Os estudos do campo de velocidade ascensional com o uso de velocimetria a laser mostraram-se coerentes com previsões obtidas de aproximações teóricas. A maior diferença observada entre os valores teóricos e experimentais foi da ordem de apenas $20 \%$, o que representa um aspecto positivo desta comparação.

É recomendado estudar as situações que implicam em eficiência máxima de transferência de massa da fase gasosa para a fase líquida. Foi possível inferir que há um ponto de máximo para alguma vazão entre $400 \mathrm{~L} / \mathrm{h}$ e $800 \mathrm{~L} / \mathrm{h}$, para a profundidade líquida de $1,80 \mathrm{~m}$.

A busca de correlações de aplicação geral deve estar sempre presente. Assim, efetuar correlações fundamentadas em parâmetros adimensionais relevantes, tanto para processos de transferência puramente físicos, como para processos de transferência envolvendo reações químicas, deve ser uma meta sempre perseguida.

\section{REFERÊNCIAS}

AMERICAN SOCIETY OF CIVILENGINEERS ASCE STANDARD - Measurement of oxygen transfer in clean water, p. 39, July. 1984.

GULLIVER, J.S.; RINDELS, A.J. Measurement of air-water oxygen transfer at hydraulic structures. Journal of Hydraulic Engineering, v. 119, n ${ }^{\circ} 3$, p. 327-349, March. 1993.

INNOCENTINI, C.K.Z. Estudo da transferência de oxigênio da fase gasosa para a fase líquida, usando difusor cerâmico poroso. Dissertaçāo (Mestrado em Hidráulica e Saneamento) - Escola de Engenharia de São Carlos, Universidade de São Paulo. São Carlos. 87p1996.

JUN, K.S.; JAIN, S.C. Oxygen transfer in bubbly turbulent-shear flow. Journal of Hydraulic Engineering, v. 119, $\mathrm{n}{ }^{\circ} 1$, p. 21-36, January. 1993.

MOMESSO, A.M. Absorção e dessorção de gases através da interface ar-água em sistemas de agitação mecânica. Dissertação (Mestrado em Hidráulica e Saneamento) - Escola de Engenharia de São Carlos, Universidade de São Paulo. São Carlos. 145p. 1996.

MOTARJEMI, M.; JAMESON, G.J. Mass transfer from very small bubbles - The optimum bubble size for aeration. Chemical Engineering Science, v. 33, p. 1415-1423, june. 1978 .

SCHULZ, H.E. Investigação do mecanismo de reoxigenação da água em escoamento e sua correlação com o nivel de turbulência junto à superficie. Tese (Doutorado em Hidráulica e Saneamento) - Escola de Engenharia de São Carlos, Universidade de São Paulo. São Carlos. 516p. v2. 1989.
SINGER, P.C.; HULL, C.S. Modeling Dissolved Ozone Behavior in Ozone Contactors. Denver. AWWA Research Foundation and American Water Works Association, 273 p. 2000.

ZHOU, H.; SMITH, D.W.; STANLEY, S.J. Modeling of dissolved ozone concentration profiles in bubble columns. Journal of Environmental Engineering, v. 120, n. 4,p.821-840, july/august. 1994.

Endereço para correspondência:

Marcio Ricardo Salla

UFU -Uberlândia

Av. João Naves de Ávila, 2 I 2 I,

Bloco IY, Campus Santa Mônica-

Uberlândia

38400-902 Uberlândia - MG -

Brasil

Tel.: (34) 3239-4 I 70 ramal 227

Fax.: (34) 3239-4159

E-mail: mrsalla@feciv.ufu.br 